\title{
O.S.P.
}

L'orientation scolaire et professionnelle

$45 / 2$ | 2016

Identité sociale et dynamique du projet

\section{Introduction - Identité sociale et dynamique du projet}

Anne-Marie Costalat-Founeau et Even Loarer

\section{OpenEdition}

\section{Journals}

Édition électronique

URL : https://journals.openedition.org/osp/4969

DOI : 10.4000/osp.4969

ISSN : 2104-3795

Éditeur

Institut national d'étude du travail et d'orientation professionnelle (INETOP)

Édition imprimée

Date de publication : 15 juin 2016

ISSN : 0249-6739

Référence électronique

Anne-Marie Costalat-Founeau et Even Loarer, «Introduction - Identité sociale et dynamique du projet », L'orientation scolaire et professionnelle [En ligne], 45/2 | 2016, mis en ligne le 01 juin 2018, consulté le 23 mai 2022. URL : http://journals.openedition.org/osp/4969 ; DOl : https://doi.org/ 10.4000/osp.4969

Ce document a été généré automatiquement le 23 mai 2022.

(c) Tous droits réservés 


\title{
Introduction - Identité sociale et dynamique du projet
}

\author{
Anne-Marie Costalat-Founeau et Even Loarer
}

Dans nos sociétés postmodernes, la multiplication des changements organisationnels et la complexification des parcours professionnels amènent à s'interroger sur les liens entre la construction identitaire et les insertions sociales et professionnelles. Ces nouvelles réflexions font la part belle à l'autodétermination, à la connaissance de soi et à l'adaptabilité (Hall, 1974), mais aussi aux capacités d'action et attitudes permettant aux individus de recréer, à travers leur propre système de valeurs, ce que la société ne leur garantit plus a priori: le sens et la cohérence de leur trajectoire sociale et professionnelle. Cela modifie, dans le sens d'un glissement du collectif vers l'individuel, l'équilibre entre deux logiques de production des identités activant les représentations qui y sont associées: d'un côté la logique subjective motivée par l'importance du contrôle que peut exercer le sujet sur la détermination du sens de ses actes, de ses choix sociaux et professionnels et de l'autre, l'influence normative qu'exercent les organisations et la société sur les formulations de projets individuels et sur l'orientation des conduites pour leur mise en œuvre.

2 L'identité se développe dans une dynamique représentationnelle jalonnée de phases de transitions plus ou moins cohérentes, au cours desquelles le sujet modifie ou réajuste son projet professionnel. Dans ces contextes souvent en changement, on constate que l'action et ses effets capacitaires émergeants sont déterminants dans la construction des identités professionnelles.

3 On peut considérer avec Sainsaulieu que la dynamique identitaire est activée par la représentation du "projet du soi », dans plusieurs sphères d'activités au travail et hors travail : « l'avenir dépend de la capacité subjective de ses membres à se construire une histoire personnelle au carrefour d'engagements multiples et diversifiés » (Sainsaulieu, 2008, p. 91).

4 Ce numéro thématique présente un ensemble de recherches portant sur des situations sociales naturelles qui permettent d'observer les mécanismes de construction identitaire en relation avec des transitions socioprofessionnelles. Les diverses 
contributions montrent ainsi, de différentes façons, comment des situations de changement dans la vie personnelle ou professionnelle impliquant des transitions professionnelles sont liées à des modifications des trajectoires identitaires professionnelles des individus et quels sont les facteurs qui influencent cette dynamique. Cela est illustré par Faurie et Costalat-Founeau sur des femmes exerçant des métiers atypiques, par Thorel, Vayre et Vonthron sur des cadres repatriés ou encore par Lahrizi, Masdonati, Skakni et Fournier sur des écoliers en transition pour l'emploi. La dynamique des transitions peut dans certains cas influencer des phases identitaires plus ou moins conflictuelles. Elle peut générer par exemple des bouleversements, des états anxieux, de perte de repères et de repli sur soi, comme le présentent Mezza, Lhuilier et Loarer chez des personnes atteintes de maladie chronique; ou encore chez des demandeurs d'emploi, décrits par Mary et CostalatFouneau. Ces derniers auteurs observent une augmentation du sentiment de frustration et un manque de confiance en soi qui provoquent une forme de repli masquant leurs capacités et leur dynamique d'expression. Cette situation a comme conséquence une forme de résignation se manifestant par un retrait, un manque de motivation décrits par les auteurs comme une phase de diffusion représentationnelle du soi. Il existe cependant des phases plus exaltantes, par exemple de recherche de nouveaux contacts, de nouveaux réseaux relationnels pour réaliser et concrétiser ses projets, qui engendrent un sentiment capacitaire positif, que les auteurs nomment phases d'acuité représentationnelle du soi, dans le sens où la situation individuelle et contextuelle se trouve clarifiée.

5 Ces différentes expressions identitaires dépendent donc des contextes, mais aussi et surtout de la capacité subjective de chacun, en relation avec son expérience et le pouvoir d'ajustement de son système capacitaire. En effet, si l'identité se développe en fonction de multiples facteurs à la fois organisationnels et personnels, nous la considérons comme une forme de résultante, émergeant certes des représentations mais aussi de l'action qui ne se réduit pas à une simple exécution de la tâche soumise au contrôle normatif et organisationnel, mais principalement à la concrétisation des capacités de l'acteur, qui conditionnent son autonomie, en relation avec ses intentions, ses désirs et ses projets. L'importance du pouvoir structurant de l'activité est primordiale comme on peut le voir par exemple dans l'étude de Mezza et al.

6 La diversité des approches épistémologiques et des terrains choisis pour ces recherches apporte ici une vision à la fois riche et stimulante de la thématique abordée. 